\title{
Projected Future Seasonal Changes in Tropical Summer Climate
}

\author{
ADAM H. SOBEL \\ Department of Applied Physics and Applied Mathematics, Department of Earth and Environmental Sciences, \\ and Lamont-Doherty Earth Observatory, Columbia University, Palisades, New York \\ SUZANA J. CAMARGO \\ Lamont-Doherty Earth Observatory, Columbia University, Palisades, New York
}

(Manuscript received 23 March 2010, in final form 6 September 2010)

\begin{abstract}
The authors analyze changes in the tropical sea surface temperature (SST), surface wind, and other fields from the twentieth to the twenty-first century in climate projections using the Coupled Model Intercomparison Project phase 3 (CMIP3) multimodel ensemble, focusing on the seasons January-March (JFM) and July-September (JAS). When the annual mean change is subtracted, the remaining "seasonal changes" have robust, coherent structures. The JFM and JAS changes resemble each other very closely after either a change of sign or reflection about the equator. The seasonal changes include an increase in the summer hemisphere SST and a decrease in the winter hemisphere SST. These appear to be thermodynamic consequences of easterly trade winds strengthening in the winter subtropics and weakening in the summer subtropics. These in turn are associated with the weakening and expansion of the Hadley circulation, documented by previous studies, which themselves are likely consequences of changes in extratropical eddies. The seasonal SST changes influence the environment for deep convection: peak precipitation in the summer hemisphere increases by around $10 \%$ and convective available potential energy (CAPE) increases by as much as $25 \%$. Comparable fractions of these changes are attributable to the annual mean change and the seasonal changes, though the two have very different spatial structures. Since the annual mean change is marked by relative warming in the Northern Hemisphere compared to the Southern Hemisphere, the seasonal changes oppose the annual mean change in JFM and enhance it in JAS.
\end{abstract}

\section{Introduction}

Projections of future climate change are largely based on simulations with comprehensive numerical models of the climate system. The coordinated experiments done with many models as part of the Intergovernmental Panel on Climate Change (IPCC) process-and the open-access data policy and infrastructure, which have made the output from those experiments widely available — have generated a unique dataset, the World Climate Research Programme (WCRP)'s Coupled Model Intercomparison Project phase 3 (CMIP3) multimodel dataset. These data can be used to explore what these numerical models can tell us about what changes may occur because of anthropogenic or natural

Corresponding author address: Adam Sobel, Department of Applied Physics and Applied Mathematics, Columbia University, 500 W. 120th St., Rm. 217, New York, NY 10027.

E-mail: ahs129@columbia.edu forcings and about the physics of the climate system. Of particular interest are changes that are robust, meaning that most or all models simulate them (albeit with differences in detail) when a common forcing is imposed. Although robustness is not a guarantee that a particular change will actually occur in response to increased greenhouse gases, it is sufficient reason to study that change carefully. Our confidence in robust changes is, of course, greater than in nonrobust ones. Additionally, as the current generation of climate models is our most important tool for generating detailed projections of future climate, it would be important that we understand robust features of those projections even if we knew they were wrong. In that case, such understanding would be the first step toward fixing the model deficiencies responsible for them. In practice, we have no independent way of determining with certainty which projections are correct and which are not, so robust projections - particularly those for which we have some physical understanding of the responsible 
mechanisms-remain our best guesses as to what will actually occur in the future.

The most robust change in response to greenhouse gases is, of course, the increase in global mean temperature; however, there are a number of others (some of which have been observed in recent historical trends as well), including the following:

1) Global mean increase in specific humidity, close to what would be expected from an assumption of fixed relative humidity (e.g., Held and Soden 2000; Soden et al. 2005; Sherwood et al. 2010a);

2) Expansion of the Hadley circulation $(\mathrm{Hu}$ and $\mathrm{Fu} 2007$; $\mathrm{Lu}$ et al. 2007; Johanson and Fu 2009) and associated poleward shift of the westerly midlatitude jets (Kushner et al. 2001; Yin 2005; Lorenz and DeWeaver 2007; Ihara and Kushnir 2009);

3) Weakening of the Walker circulation (Held and Soden 2006; Vecchi et al. 2006);

4) Delay of the seasonal cycle over much of the tropics (Biasutti and Sobel 2009; Seth et al. 2010, 2011);

5) Further concentration of precipitation in places that are already rainy and drying in places that are already dry (Neelin et al. 2003; Chou et al. 2006; Held and Soden 2006);

6) Changes in the relative humidity field that, though small, share a common spatial structure across models (Richter and Xie 2008; Sherwood et al. 2010b; Wright et al. 2010; Hurley and Galewsky 2010); and

7) Changes in the sea surface temperature (SST) field that share a common spatial structure across models (Liu et al. 2005; Vecchi and Soden 2007; Leloup and Clement 2009; Clement et al. 2010).

Xie et al. (2010) show the annual mean changes in SST in two models and discuss their causes. Perhaps most prominent are warming along the equatorial Pacific (reminiscent of an El Niño event, though the underlying dynamics are somewhat different; see also DiNezio et al. 2009) and warming of the Northern Hemisphere relative to the Southern Hemisphere. Xie et al. (2010) show that the warming of the Northern Hemisphere relative to the Southern Hemisphere is responsible for a similar relative increase in the Northern Hemisphere of both tropical cyclone potential intensity and a measure of moist convective instability. The north-south dipole structure in potential intensity was also shown to be present in the JuneNovember multimodel climatological change from the CMIP3 multimodel dataset ensemble by Vecchi and Soden (2007). Xie et al. (2010) show that the annual mean SST changes are ascribable to several proximate causes, particularly ocean dynamics and surface wind speed changes.

In the present study, following and extending Xie et al. (2010), we analyze features in the CMIP3 multimodel mean of SST and a number of related atmospheric fields. Our focus is on the seasonal means for the near-solsticial seasons, when the monsoons and Hadley circulations are at their strongest (e.g., Dima and Wallace 2003), and on the latitudinal structure of the zonal mean changes. We show that the projected changes in the twenty-first century compared to the twentieth century can be described as a hemispherically asymmetric annual mean change (well described by Xie et al. 2010) plus seasonally varying components that are to a large extent antisymmetric with respect to either a change of sign or reflection about the equator. We describe the dynamics of these changes and argue that they are tropical responses to Hadley circulation changes that, in turn, have been previously documented and are likely to result at least in part from changes in extratropical dynamics.

\section{Methods}

The analysis is based on the integrations of the CMIP3 database (Meehl et al. 2007) for the twentieth and twenty-first centuries. The twentieth-century integrations (Twentieth-Century Climate in Coupled Model, named 20C3M in the dataset, hereafter 20C) are forced by the historical anthropogenic emissions of greenhouse gases and sulfate aerosols. For some models other anthropogenic and natural forcings are also considered. For the twenty-century simulations (here $21 \mathrm{C}$ ), we chose the scenario $\mathrm{A} 1 \mathrm{~B}$, which is a middle-of-the road scenario with an increase of greenhouse gases that stabilizes at $700 \mathrm{ppm}$ and an increase of sulfate aerosol emissions up to 2020 and decreasing afterward.

Our analysis will focus on the differences between the last $25 \mathrm{yr}$ of the twenty-first (2074-99) and twentieth (1974-99) centuries, similar to previous studies (e.g., Biasutti et al. 2009). When possible, we consider all 24 models of the CMIP3 database (Meehl et al. 2007). To compute convective available potential energy (CAPE) and tropical cyclone potential intensity, vertical profiles of temperature and humidity profiles are necessary. As those data are not available from all models, fewer (22) models are used to compute those variables. Only one integration of each model is considered.

The steps to compute the ensemble mean of all models available were as follows: first, data from all the models were interpolated to the same uniform grid, $2.5^{\circ}$ longitude $\times 2.5^{\circ}$ latitude. Then, the ensemble mean, annually varying monthly climatology of all models was computed for the twentieth and twenty-first centuries. That monthly climatology was then used to compute the annual, JulySeptember (JAS), and January-March (JFM) means, which are shown below. 
The tropical cyclone potential intensity (PI) was calculated using a generalization of the method described in Emanuel (1995), taking into account dissipative heating (Bister and Emanuel 1998). The PI is obtained from vertical profiles of temperature and humidity, as well as sea surface temperature and sea level pressure, as described in Bister and Emanuel (2002a,b), where its climatology for the present climate is also given. The environmental CAPE is computed as part of this algorithm.

As discussed above, we focus on the near-solsticial seasons in the twenty-first century. We write $X(21 \mathrm{C}$, JAS) to indicate the JAS climatological and multimodel ensemble mean of a physical field $X$ in the JAS season in the last $25 \mathrm{yr}$ of the twenty-first century. It proves useful to write the decomposition

$$
\begin{aligned}
X(21 \mathrm{C}, \mathrm{JAS})= & X(20 \mathrm{C}, \mathrm{JAS})+\Delta X(\mathrm{AM}) \\
& +[\Delta X(\mathrm{JAS})-\Delta X(\mathrm{AM})],
\end{aligned}
$$

where $X(20 \mathrm{C}, \mathrm{JAS})$ is the multimodel ensemble mean climatology for JAS in the last $25 \mathrm{yr}$ of the twentieth century; $\Delta X(\mathrm{AM})$ is the change in the annual mean climatology from the twentieth to the twenty-first century (i.e., the twenty-first-century annual mean minus the twentieth-century annual mean); and $\Delta X(\mathrm{JAS})$ is the change in the JAS climatology (i.e., the twenty-firstcentury JAS climatology minus the twentieth-century JAS climatology). For compactness, we define

$$
\delta X(\mathrm{JAS})=\Delta X(\mathrm{JAS})-\Delta X(\mathrm{AM})
$$

so that (1) becomes

$$
X(21 \mathrm{C}, \mathrm{JAS})=X(20 \mathrm{C}, \mathrm{JAS})+\Delta X(\mathrm{AM})+\delta X(\mathrm{JAS})
$$

The quantity $\delta X$ (JAS) is the change in the JAS climatology of field $X$ from the twentieth to the twenty-first century minus the annual mean change in that field. To consider the JFM season, we simply substitute JFM for JAS in the above definitions. We refer to this change simply as the "seasonal change" in field $X$, recognizing that it does not include the annual mean change. We refer to $\Delta X(\mathrm{JAS})$ as the "total seasonal change" for the season JAS.

We will show that the fields $\delta X$, with $X$ sea surface temperature, surface wind speed $(1000 \mathrm{hPa})$, individual surface wind components $(1000 \mathrm{hPa})$, precipitation, and other related fields, indicate a response of the tropical climate system that is coherent, largely independent of the annual mean changes, and can be interpreted as a response to previously documented, extratropically mediated changes in the Hadley circulation.

\section{Results}

\section{a. Latitude-longitude structure of SST and surface wind speed changes}

Figure 1 shows the twentieth-century climatology SST (20C, JAS), the SST annual mean change $\Delta$ SST(AM), and the SST seasonal changes $\delta \mathrm{SST}(\mathrm{JAS}), \delta \mathrm{SST}(\mathrm{JFM})$. The latter two correspond to the latter two terms on the rhs of (2), with the last term evaluated for JAS and JFM, respectively.

The annual mean SST change shows a local maximum in warming in the equatorial Pacific, a north-south asymmetry with greater warming in the Northern Hemisphere than the Southern Hemisphere, and other regional details, such as a minimum in warming off the southwestern coast of South America; these features are discussed by Liu et al. (2005), DiNezio et al. (2009), and Xie et al. (2010), but we do not discuss them in detail here. Of greater interest to us are the bottom two panels of Fig. 1, which show the seasonal changes in JFM and JAS. These have very similar structures, except with a change of sign or, alternatively, a reflection about the equator. By definition, for any $X, \delta X(\mathrm{JSM})+\delta X(\mathrm{AMJ})+\delta X(\mathrm{JAS})+$ $\delta X(\mathrm{OND})=0$, so the symmetry with respect to sign change implies that either $\delta$ SST is small for April-June $(\mathrm{AMJ})$ and October-December (OND), or also symmetric for those two seasons with respect to a sign change; the latter is more nearly the case, as the amplitudes of the changes in these seasons are comparable in magnitude to those in JAS and JFM (not shown). The symmetry with respect to reflection about the equator does not have any simple mathematical explanation, but it presumably reflects the fact that the seasonal changes are greenhouse gas-induced alterations of the natural seasonal cycle, which itself has this symmetry to a large degree.

In JAS, the seasonal change in SST is a warming in the Northern Hemisphere and cooling in the Southern Hemisphere. This adds constructively to the annual mean change to increase the cross-equatorial SST contrast. In JFM there is a warming in the Southern Hemisphere and cooling in the Northern Hemisphere. This adds destructively to the annual mean change to reduce the crossequatorial SST contrast, though the annual mean change is sufficiently large that altogether, even in JFM the Northern Hemisphere warms more than the Southern Hemisphere in the twenty-first century compared to the twentieth century. The largest changes occur around $40^{\circ} \mathrm{N}$ in JFM and $40^{\circ} \mathrm{S}$ in JAS, but the signs of the changes are almost entirely uniform within each hemisphere.

Figure 2 has the same format as Fig. 1 but shows the surface wind speed $(1000 \mathrm{hPa})$ instead of SST. The wind speed is calculated from the monthly-mean vector winds; the effect of submonthly fluctuations in the zonal 
(a)

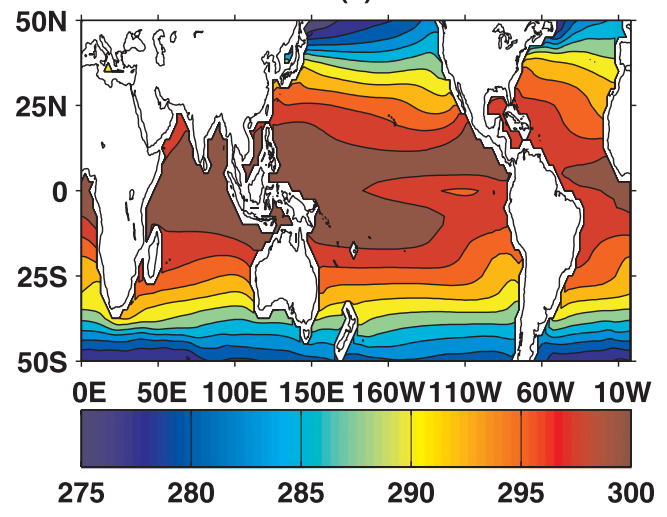

(c)

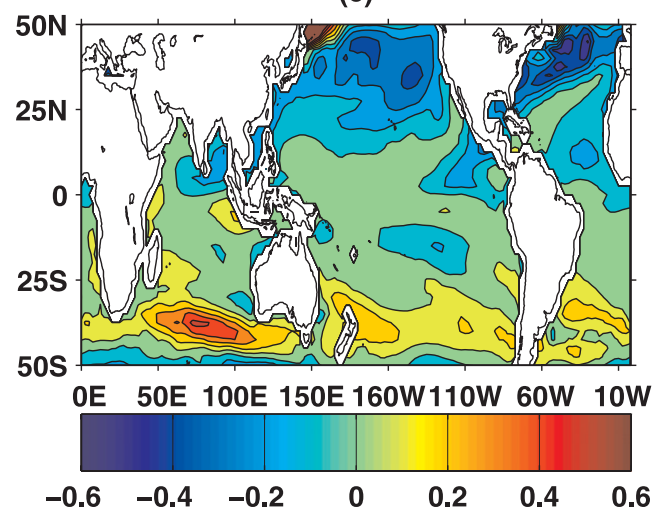

(b)

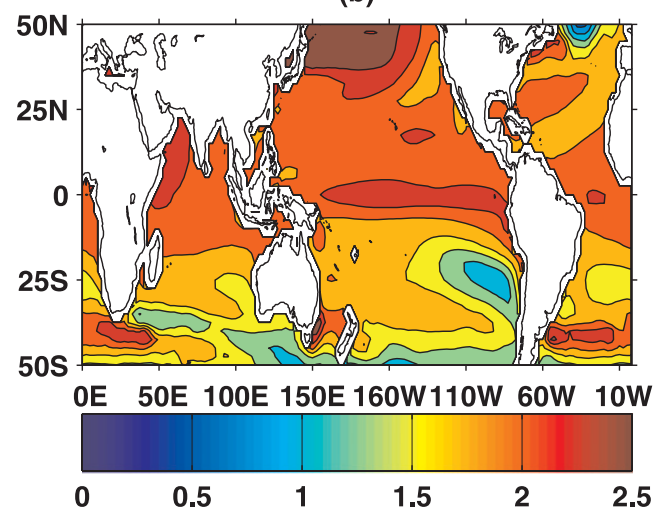

(d)

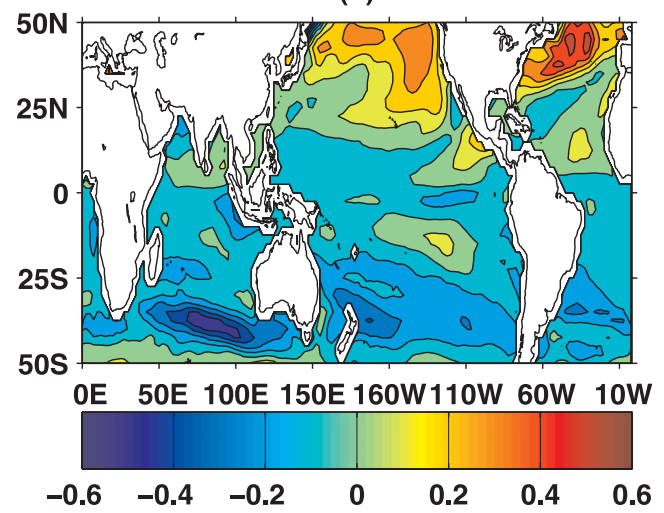

FIG. 1. (a) SST annual mean climatology $20 \mathrm{C}[\mathrm{SST}(20 \mathrm{C}, \mathrm{AM})]$ (contour interval $\left.=2.5^{\circ} \mathrm{K}\right)$. (b) SST annual mean change $[\Delta \mathrm{SST}(\mathrm{AM})]$ (contour interval $\left.=0.25^{\circ} \mathrm{C}\right)$. (c) SST seasonal changes in JFM $[\delta \mathrm{SST}(\mathrm{JFM})]($ contour interval $=$ $0.1^{\circ} \mathrm{C}$ ). (d) SST seasonal changes in JAS $[\delta \mathrm{SST}(\mathrm{JAS})]$ (contour interval $=0.1^{\circ} \mathrm{C}$ ); see text for definitions.

and meridional winds $u$ and $v$ on the wind speed $V=$ $\left(u^{2}+v^{2}\right)^{1 / 2}$ are not included. (We have performed the same calculations using daily wind speed for the subset of models for which daily winds are available. The results are quite similar to those shown in Fig. 2. We show monthlymean winds because they can be more directly related to changes in the time-mean Hadley circulation, which is central to our interpretation.) The twentieth-century annual mean climatology shows weak winds near the equator and near $30^{\circ} \mathrm{S}$ and $30^{\circ} \mathrm{N}$, where the transition from mean easterlies to westerlies tends to occur, and stronger winds near $20^{\circ} \mathrm{S}$ and $20^{\circ} \mathrm{N}$, where the easterly trades dominate. The annual mean change shows weakening winds in the equatorial belt (Vecchi et al. 2006; DiNezio et al. 2009) and in most of the Northern Hemisphere, as well as around $35^{\circ} \mathrm{S}$, but strengthening of the southern trades, particularly in the Pacific (Xie et al. 2010). The seasonal changes again tend to enhance the annual mean change in JAS and oppose it in JFM. In JFM, we see weakening winds in the southern summer subtropics (equatorward of $30^{\circ} \mathrm{S}$ ) and tropics; the Northern Hemisphere shows a banded structure with about $10^{\circ}$ of latitude between local maxima and minima; there is weakening around $10^{\circ} \mathrm{N}$, strengthening around $20^{\circ} \mathrm{N}$, weakening at $30^{\circ} \mathrm{N}$, and strengthening at $40^{\circ} \mathrm{N}$. The pattern in JAS is very nearly the reverse of this.

Figure 3 shows the consensus across the CMIP3 ensemble regarding the SST and surface wind speed changes. The quantity plotted is the fraction of models in the ensemble whose anomaly in the seasonal change is of the same sign, with the sign attributed to the majority. Thus, a value of -0.6 means $60 \%$ of the models have a negative anomaly. With values exceeding 0.7 in the regions of the largest ensemble mean anomalies, these plots indicate that the changes shown in Figs. 1 and 2 are robust across the ensemble.

\section{b. Zonal mean changes}

As the structures shown in the bottom two panels of Figs. 1 and 2 exhibit a degree of zonal symmetry, we now 
(a)

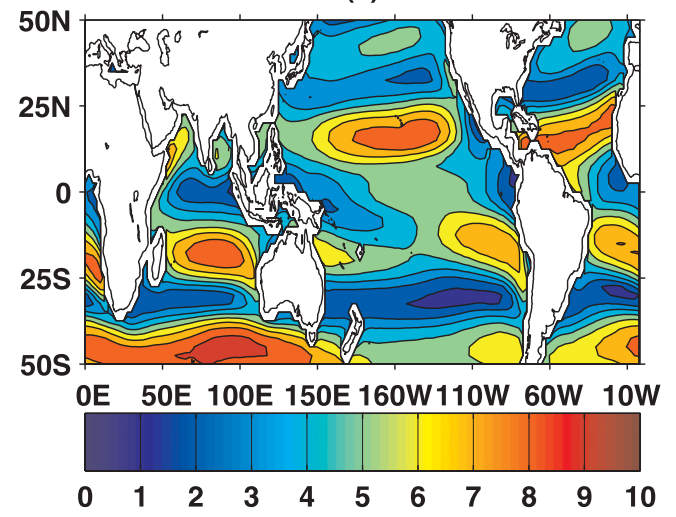

(c)

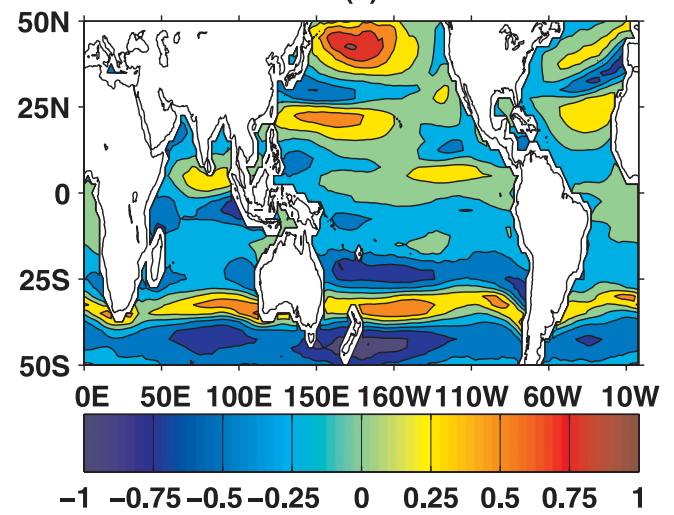

(b)

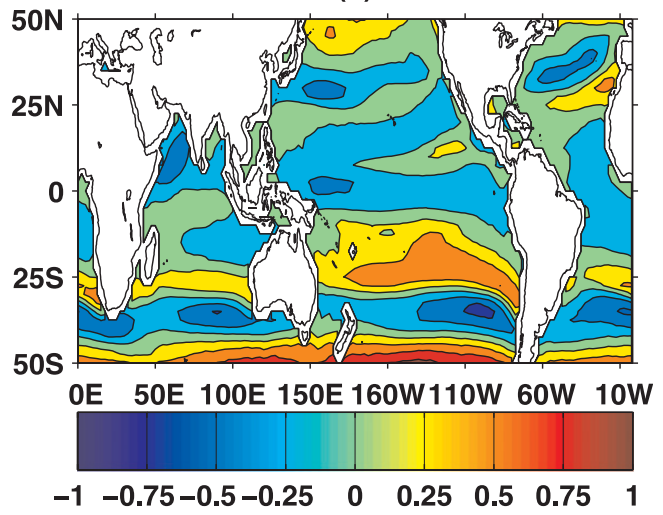

(d)

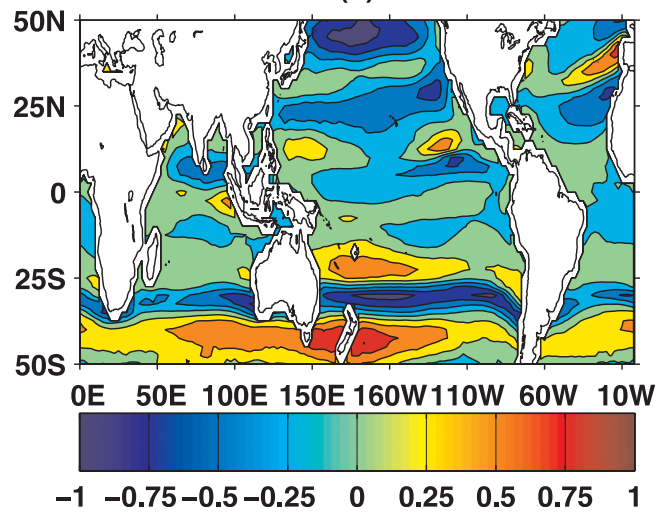

FIG. 2. (a) Surface wind speed annual mean climatology $20 \mathrm{C}[V(20 \mathrm{C}, \mathrm{AM})]$ (contour interval $\left.=1 \mathrm{~m} \mathrm{~s}^{-1}\right)$. (b) Surface wind speed annual mean change $[\Delta V(\mathrm{AM})]$. (c) Surface wind speed seasonal changes in JFM $[\delta V(\mathrm{JFM})]$. (d) Surface wind speed seasonal changes in JAS $[\delta V$ (JAS)]; see text for definitions. Contour interval in (b) $-(\mathrm{d})$ is $0.25 \mathrm{~m} \mathrm{~s}^{-1}$.

focus on zonal means. As our focus is on the climate over the tropical oceans, the zonal means were calculated for ocean grid points only (i.e., land points are excluded).

\section{1) SST, SURFACE WIND SPEED, AND LATENT HEAT FLUX}

Figure 4a shows the annual mean SST change, as well as the seasonal JFM and JAS SST changes. The annual mean change again shows the equatorial warming and greater warming in the Northern Hemisphere than in the Southern Hemisphere. The seasonal changes in JAS and JFM are simple in structure and remarkably similar to each other, apart from the change in sign. There is a relative warming in the summer hemisphere and cooling in the winter, with maxima in both near $40^{\circ}$ latitude. The peak magnitude in the tropics is around $0.2^{\circ} \mathrm{C}$. This is large enough to influence the atmosphere in a significant way (recognizing that these are multimodel ensemble means of changes in 25-yr seasonal climatologies).

Figure $4 \mathrm{~b}$ has the same format as Fig. 4a, but it shows wind speed. We again see the expected annual mean wind speed increase in the Southern Hemisphere relative to the Northern Hemisphere. The seasonal changes, as expected from Fig. 2, show oscillations superimposed on the overall north-south gradients within the tropics; larger changes in both the annual means and the seasonal changes are apparent at mid- and high southern latitudes.

Figure $4 \mathrm{c}$ shows the seasonal changes in SST and wind speed together, with the $x$ axis magnified so that only latitudes between $30^{\circ} \mathrm{S}$ and $30^{\circ} \mathrm{N}$ are shown. Note that only one vertical axis is needed in the figure, as it so happens that the changes in wind speed (in $\mathrm{m} \mathrm{s}^{-1}$ ) are similar in magnitude to the changes in SST $\left(\right.$ in ${ }^{\circ} \mathrm{C}$ ). We see from this panel that the trends with latitude in wind speed and SST are similar but opposite. The oscillations are also present in both and are approximately out of phase; however, 
(a) SST consensus JFM

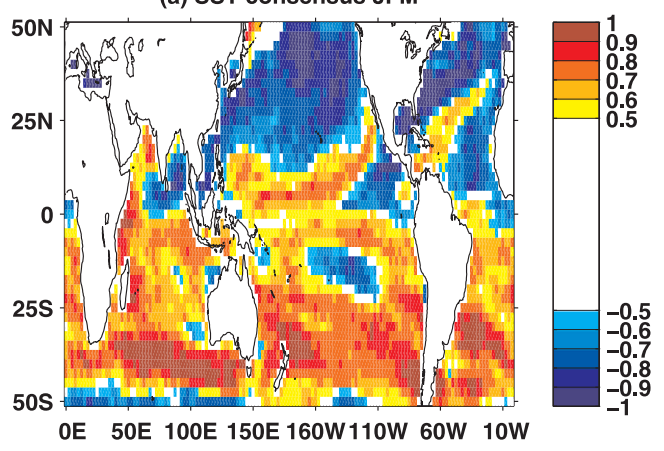

(c) Wind speed consensus JFM
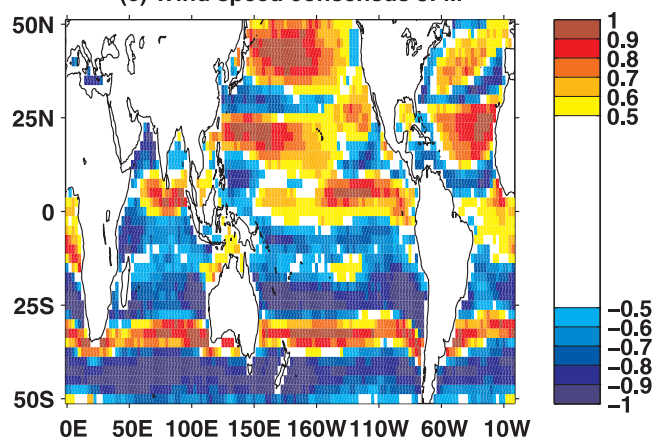

(b) SST consensus JAS

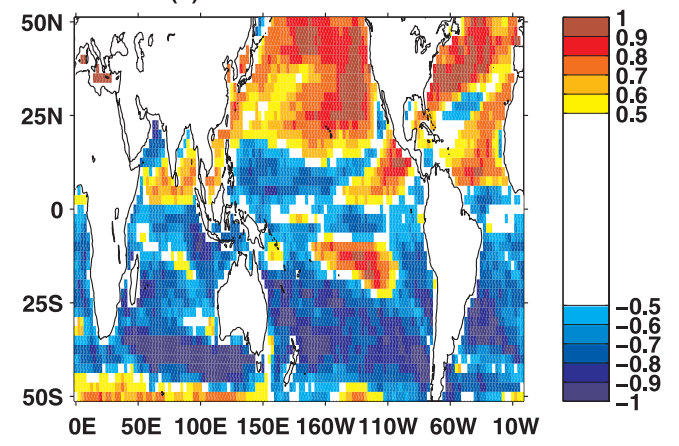

(d) Wind speed consensus JAS

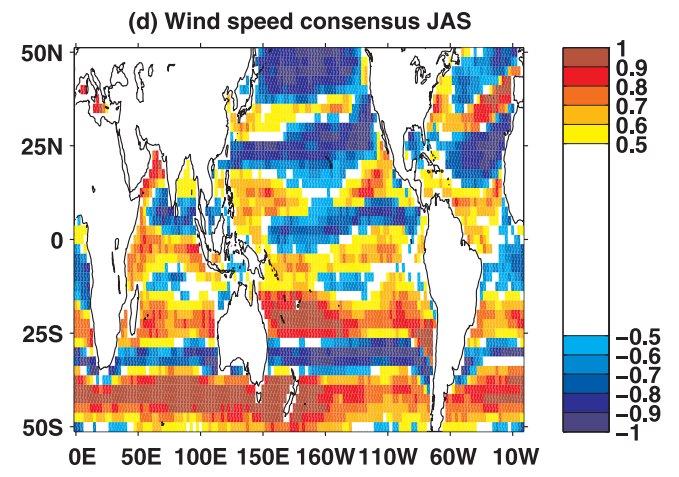

FIG. 3. Model consensus: percentage of models in the ensemble whose seasonal changes are of the same sign at each grid point, with that sign being the sign plotted, for SST in (a) JFM and (b) JAS and for wind speed in (c) JFM and (d) JAS.

they are much weaker in SST than in wind speed, so the signs of the SST changes do not reverse within a hemisphere although the signs of the wind speed changes do.

The similar magnitudes of the SST and wind speed changes when measured in International System (SI) units as shown in Fig. $4 \mathrm{c}$ are a coincidence resulting from the values of several constants of nature as well as the typical values of the relevant physical variables in the earth's tropics. The latent heat flux $E$ is typically parameterized by a bulk formula:

$$
E=L \rho_{a} C V\left[q^{*}(\mathrm{SST})-q_{a}\right]
$$

where $E$ is measured in watts per meter squared, $L$ is the latent heat of vaporization, $\rho_{a}$ is the surface air density $\left(\mathrm{kg} \mathrm{m}^{-3}\right), C$ is the (dimensionless) bulk exchange coefficient, $V$ is the surface wind speed $\left(\mathrm{m} \mathrm{s}^{-1}\right), q^{*}(\mathrm{SST})$ is the saturation specific humidity evaluated at the SST and surface pressure, and $q_{a}$ is the surface air specific humidity (the latter two both measured in $\mathrm{kg} \mathrm{kg}^{-1}$ ). With typical values for all the quantities, it so happens that a $+1^{\circ} \mathrm{C}$ change in SST leads to a change in $E$ of the same order as does a $-1 \mathrm{~m} \mathrm{~s}^{-1}$ change in wind speed, in both cases holding all other variables constant.
The simplest interpretation of the relationship between wind speed and SST is that the wind speed change drives the SST change. If the radiative fluxes, sensible surface heat fluxes, and ocean heat transport were unchanged (so that $E$ would also remain unchanged by surface energy balance), and $q_{a}$ were unchanged as well, then the wind speed changes shown in shown in Fig. 4c would be expected to lead to SST changes similar, both qualitatively and quantitatively, to those shown in that figure, apart from the lesser amplitude of the oscillations in SST compared to wind.

Figure 5 shows that while the simple picture described above may be adequate to explain the order of magnitude of the various quantities, it is not a correct description of what actually happens in the simulations. Both $E$ and the air-sea humidity difference $\left[q^{*}(\mathrm{SST})-q_{a}\right]$ do change by fractional amounts comparable to those in the other variables (e.g., a $0.1 \mathrm{~m} \mathrm{~s}^{-1}$ change in wind speed is $1 \%$ if the mean wind speed is $10 \mathrm{~m} \mathrm{~s}^{-1}$, while a $1 \mathrm{~W} \mathrm{~m}^{-2}$ change in latent heat flux is a $1 \%$ change if the mean is $100 \mathrm{~W} \mathrm{~m}^{-2}$ ). In fact, the changes in $\left[q^{*}(\mathrm{SST})-q_{a}\right]$ do not closely resemble those of the wind speed in spatial structure, while those in $E$ do. This implies that the SST changes do not result from a rebalancing of different components that 
(a)

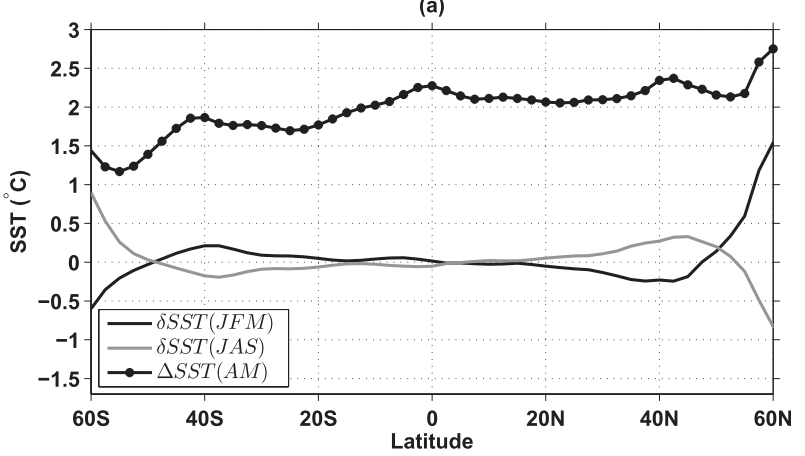

(b)

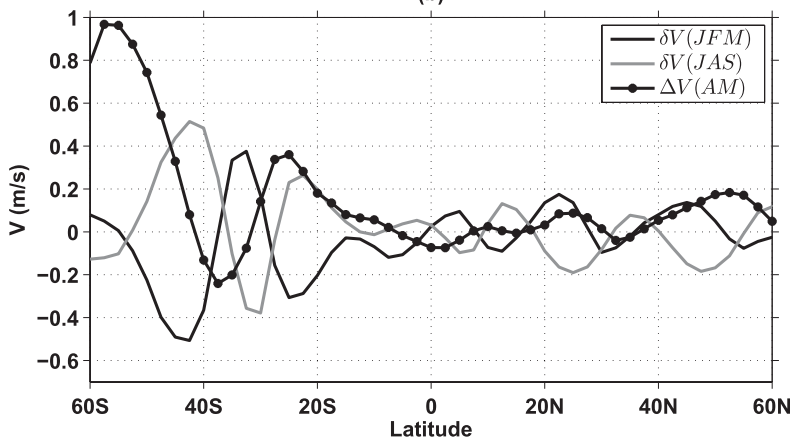

(c)

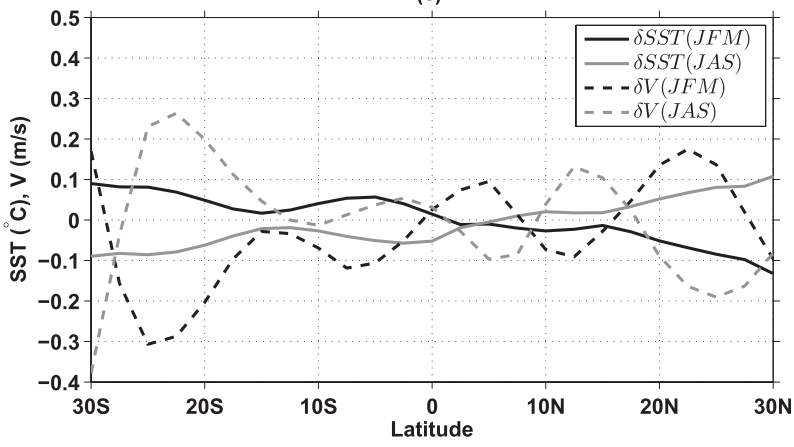

FIG. 4. (a) Seasonal changes [ $\delta \mathrm{SST}(\mathrm{JFM}), \delta S S T(J A S)]$. (b) Annual mean change in zonal mean wind speed $[\Delta V(\mathrm{AM})]$ and seasonal changes $[\delta V(\mathrm{JFM}), \delta V(\mathrm{JAS})]$. (c) Zonal mean seasonal changes in SST $[\delta \mathrm{SST}(\mathrm{JFM}), \delta \mathrm{SST}(\mathrm{JAS})]$ and wind speed $[\delta V$ $(\mathrm{JFM}), \delta V(\mathrm{JAS})]$ for $30^{\circ} \mathrm{S}-30^{\circ} \mathrm{N}$ only.

control $E$ but rather from wind-induced changes in $E$ itself. These may increase the tendency of SST (remembering that we are looking at the seasonal cycle rather than a statistically steady state) or be compensated in whole or in part by some other component of the surface energy budget (which we do not analyze here). Nonetheless, the causal picture in the above discussion, in which wind speed drives the change in SST, still appears the most plausible. Wind speed is controlled nonlocally by the entire circulation, and it is much easier to imagine how wind speed change can induce local changes in SST-via changes in the latent heat flux, as are shown to occur in Fig. 5than the converse. (a)

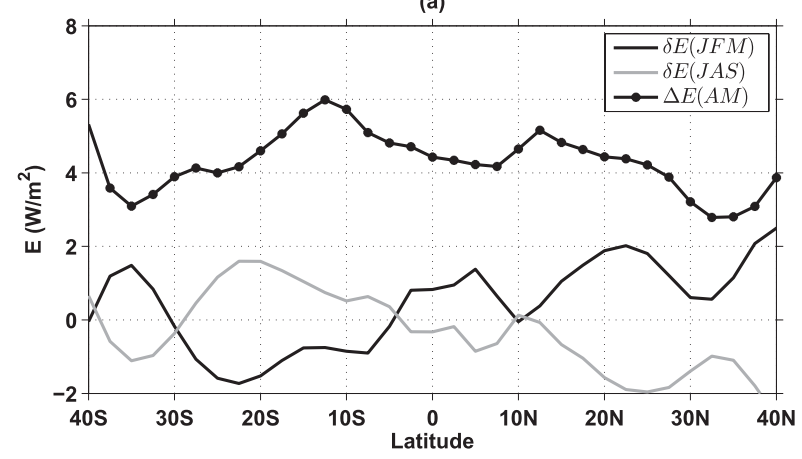

(b)

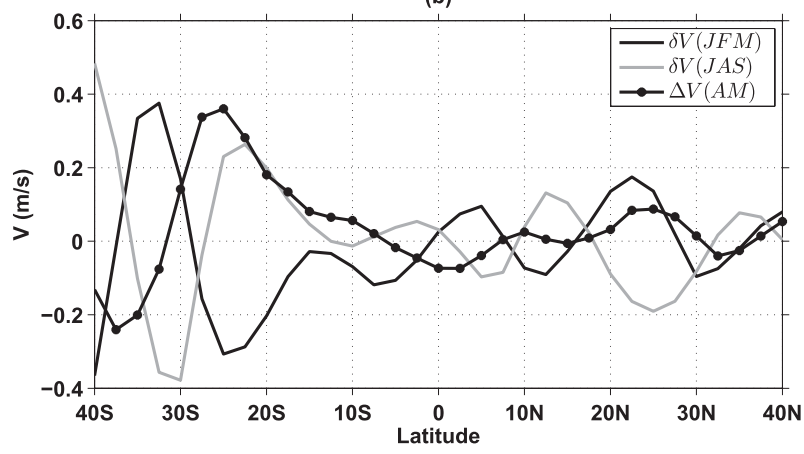

(c)

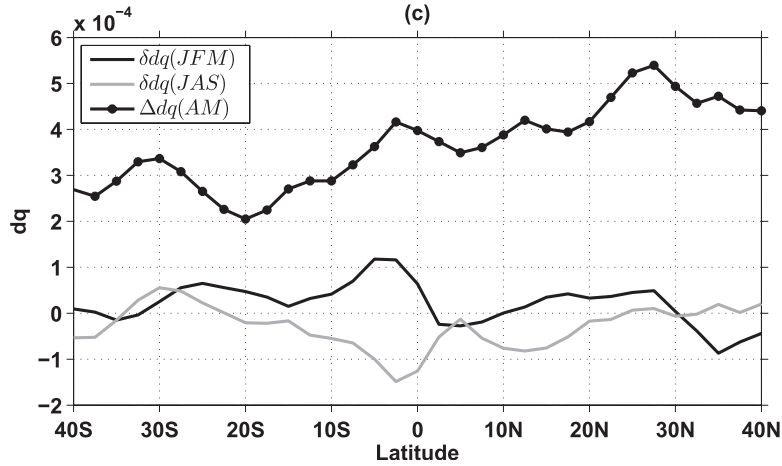

FIG. 5. (a) Zonal mean surface latent heat flux annual change $[\Delta E(\mathrm{AM})]$ and seasonal changes $[\delta E(\mathrm{JFM}), \delta E(\mathrm{JAS})]$. (b) Zonal mean wind speed annual mean change $[\Delta V(\mathrm{AM})]$ and seasonal changes $[\delta V(\mathrm{JFM}), \delta V(\mathrm{JAS})]$. (c) Zonal mean specific humidity difference $\left\{\left[d q=q^{*}(\mathrm{SST})\right]-q_{a}\right\}$ annual mean change $[\Delta d q(\mathrm{AM})]$ and seasonal changes $[\delta d q(\mathrm{JFM}), \delta d q(\mathrm{JAS})]$.

\section{2) SURFACE WIND COMPONENTS}

Figure 6 shows zonal mean plots of the zonal and meridional components of the surface wind. The top and middle panels show the zonal (Figs. 6a and $6 \mathrm{~b}$ ) and meridional (Figs. $6 \mathrm{c}$ and $6 \mathrm{~d}$ ) wind for JFM (left) and JAS (right). In each of these plots, the dashed curve shows the climatology for the twentieth century for the season in question, the solid curve with dots shows the change in the annual mean climatology (thus this curve is the same in the left and right panels), and the solid curve without dots shows the seasonal change for the season in question. 
(a)

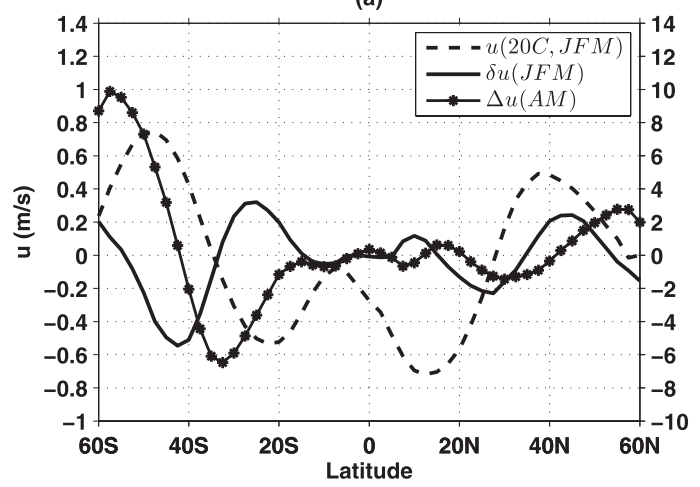

(c)

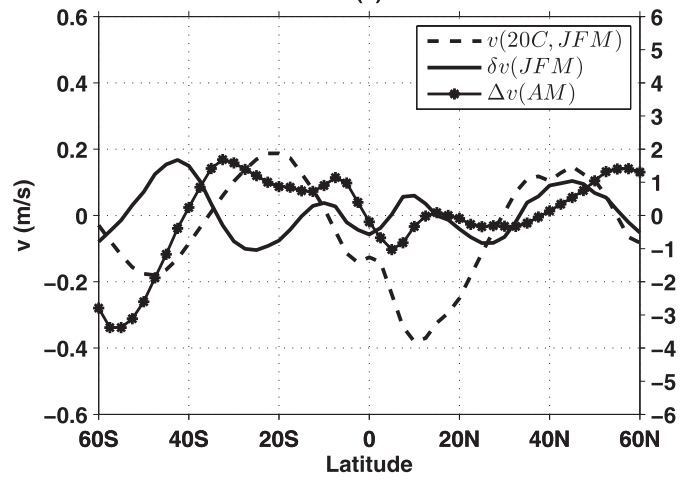

(e)

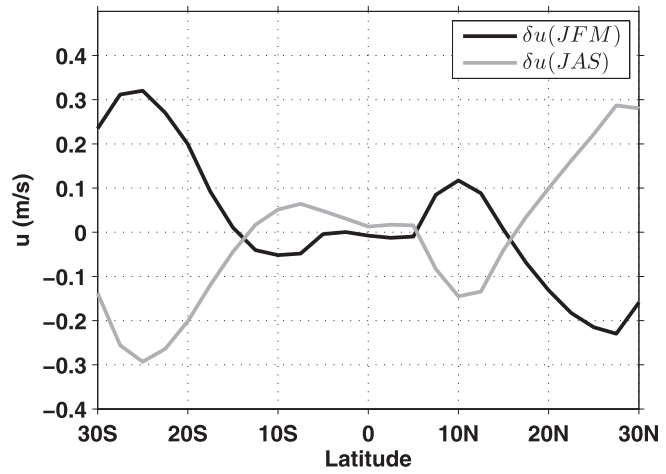

(b)

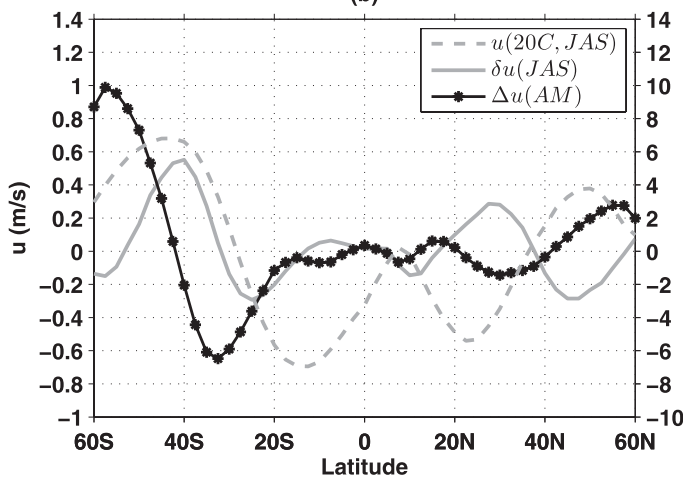

(d)

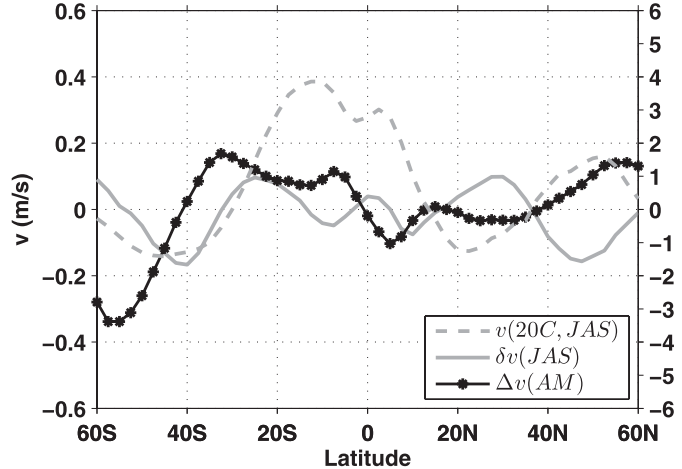

(f)

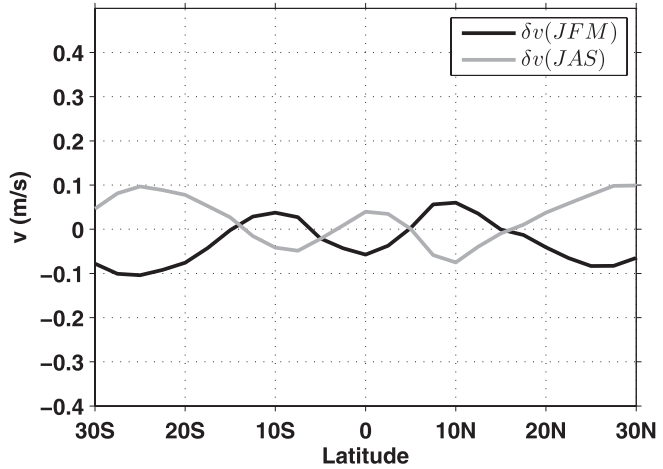

FIG. 6. (top) Zonal mean zonal wind climatology 20C [ $u(20 \mathrm{C})]$, seasonal change $(\delta u)$ for (a) JFM and (b) JAS, and annual mean change $[\Delta u(\mathrm{AM})]$. (middle) Zonal mean meridional wind climatology $20 \mathrm{C}[v(20 \mathrm{C})]$, seasonal change $(\delta v)$ for (c) JFM and (d) JAS, and annual mean change $[\Delta v(\mathrm{AM})]$. (e) Zonal mean seasonal changes for zonal wind $[\delta u(\mathrm{JFM}), \delta u(\mathrm{JAS})]$ and (f) meridional wind $[\delta u(\mathrm{JFM}), \delta u(\mathrm{JAS})]$ in the tropics only.

Figures $6 \mathrm{e}$ and $6 \mathrm{f}$ show the same quantities as in the solid curves in the top panels (seasonal changes; darker curves for JFM, lighter curves for JAS) but with axes spanning narrower ranges in both latitudes and wind magnitude.

Focusing first on the zonal wind, we see that the annual mean changes would correspond to a broadening of the subtropical easterlies in both hemispheres and seasons. The broadening is associated with a strengthening of the easterlies near their most poleward extent, since that is the point at which they vanish in the twentieth-century climatology (as the zonal winds change sign from easterly to westerly). The seasonal changes in both seasons in the winter hemisphere can best be described as an additional expansion and strengthening of the winter subtropical easterlies, a strengthening and slight poleward shift of the winter midlatitude westerlies, and a decrease in zonal wind magnitude between those two as the "horse latitudes" demarcating the transition from easterlies to westerlies also shift poleward. In the summer hemisphere, the subtropical easterlies weaken.

The meridional wind changes are consistent with the zonal wind changes. The largest meridional wind changes 
in the subtropics can be described as a poleward expansion of the region of equatorward flow in the winter hemisphere and a weakening of the equatorward flow in the summer hemisphere. In the deep tropics, there are changes in the meridional wind that are nearly as large as those in the subtropics, but they are not accompanied by zonal wind changes nearly as large as those in the subtropics.

The meridional wind changes near the equator are related to the SST changes in the way expected, qualitatively, from the Lindzen and Nigam (1987) model or other simple models that derive tropical surface winds from SST fields [e.g., see Sobel (2007) for a review]. For example, in Fig. $6 f$ we see increased northerlies on the equator in JAS and southerlies in JFM, consistent with the increased northward anomalous SST gradient in the former and southward in the latter. Off the equator at about $10^{\circ} \mathrm{S}$ and $10^{\circ} \mathrm{N}$, the anomalies reverse sign, consistent with the reversal (or at least flattening) of the anomalous SST gradients. Though we do not attempt to demonstrate this, it is plausible that wind-evaporationSST feedback (Xie and Philander 1994) may play a role in generating these near-equatorial changes.

The relationship between zonal and meridional surface wind changes can be understood qualitatively by assuming that the zonal mean surface winds are governed by steady linear balances:

$$
\begin{aligned}
& f v=\epsilon u \text { and } \\
& f u=-\epsilon v-\partial_{y} p,
\end{aligned}
$$

where $u$ and $v$ are (zonal and time mean) zonal and meridional wind, $\epsilon$ is an effective Rayleigh drag coefficient, $f$ is the Coriolis parameter, and $p$ is the surface pressure. Equation (4) can be written as

$$
u=\frac{f}{\epsilon} v
$$

which shows that, assuming $\epsilon$ is constant, the same change in $v$ will be associated with a larger response in $u$ farther from the equator because of the increase in the Coriolis parameter. Thus, the changes in $v$ farther from the equator will have a greater influence on total wind speed, and thus also on surface fluxes and SST.

The seasonal changes in the surface meridional winds in JFM and JAS, particularly in the regions poleward of approximately $15^{\circ}$ latitude in both hemispheres, can be summarized as an expansion of the winter Hadley cell and a weakening of the summer Hadley cell. The Coriolis torques on these changes lead to increases in the strength of the winter subtropical easterlies and decreases in the strength of the summer subtropical easterlies. The surface wind speed increases in the winter subtropics and decreases in the summer subtropics are primarily consequences of the zonal wind changes - as those are larger in magnitude than the meridional wind changes-although the latter also influence the speeds in the same sense.

The expansion of the Hadley circulation has been found not only in future climate projections but in observational studies of recent historical trends (e.g., $\mathrm{Hu}$ and $\mathrm{Fu}$ 2007; Johanson and $\mathrm{Fu} 2009$ ). The weakening of the circulation, on the other hand, has not yet been observed with confidence, showing a discrepancy between models and observations of the twentieth century (Mitas and Clement 2005, 2006). This remains simply a robust projection for the future.

\section{3) CAPE AND POTENTIAL INTENSITY}

As discussed above (and further below), the seasonal changes in SST are best viewed as forced by the changes in the atmospheric circulation, rather than as themselves determining the changes in the atmospheric circulation. However, the SST changes do have potential atmospheric consequences, as they influence the environment for deep convection and tropical cyclone formation.

Figures 7 and 8 show changes in environmental CAPE and tropical cyclone PI, both computed using the PI algorithm and code provided by K. A. Emanuel, based on Bister and Emanuel (2002a,b), for JFM and JAS. The top panels show the twentieth- and twenty-first-century climatologies of these two variables for JFM and JAS, the middle panels show the total changes (differences of the two curves in the top panels), and the bottom panels show the breakdowns of those differences into annual mean differences and seasonal differences.

As shown by Xie et al. (2010), using a simpler proxy for CAPE, the annual mean CAPE change has a broad maximum on the equator; Xie et al. showed that this structure is related to the relatively small gradients in upper-tropospheric temperature compared to those in surface moist static energy. The bottom panels show that the seasonal changes (which again are very similar in the two seasons, apart from the sign reversal) are as large as the annual mean change poleward of about $10^{\circ}$ latitude, and very different in structure than the annual mean. As a result, the total changes in JFM and JAS also have a different structure than the annual mean, with sharper maxima lying well off the equator in the summer hemisphere.

The annual mean PI change also maximizes on the equator [where tropical cyclone formation almost never occurs; PI is a purely thermodynamic quantity and does not account for the role of vorticity in tropical cyclone (TC) formation], but it is not symmetric about it, showing instead an increase in the Northern Hemisphere and the 


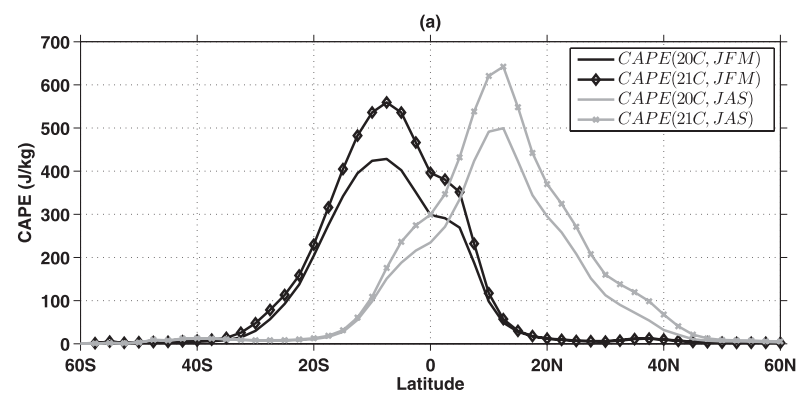

(b)

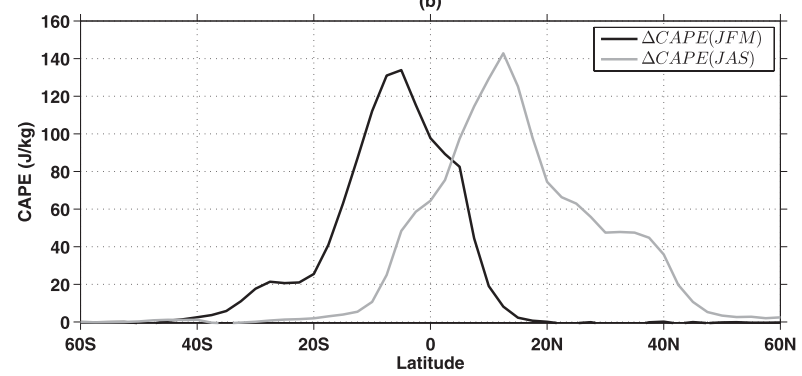

(c)

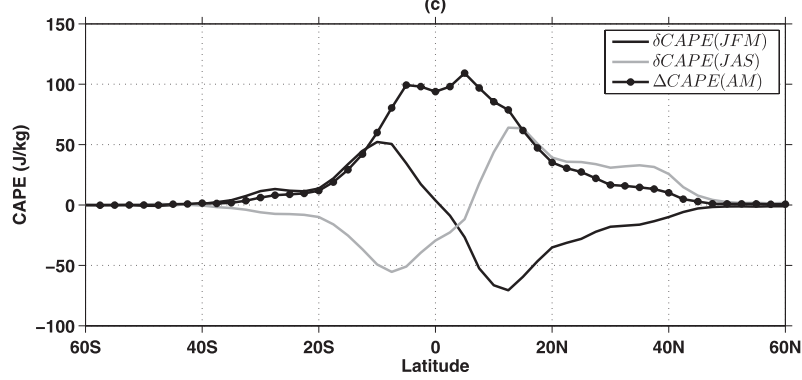

FIG. 7. (a) Zonal mean CAPE $20 \mathrm{C}$ and $21 \mathrm{C}$ for JFM and JAS. (b) Zonal mean CAPE difference 21C and 20C ( $\triangle$ CAPE) for JFM and JAS. (c) Zonal mean annual mean CAPE changes [ $\triangle \mathrm{CAPE}(\mathrm{AM})]$ and seasonal CAPE changes ( $\delta \mathrm{CAPE}$ ) for JFM and JAS.

lowest southern latitudes and a decrease poleward of about $15^{\circ} \mathrm{S}$. The seasonal changes in PI, as in other fields shown above, have similar structures in the two seasons, apart from a sign reversal, with an increase in the summer hemisphere and a decrease in the winter hemisphere; the main asymmetry is a region of small additional PI change between $0^{\circ}$ and $10^{\circ} \mathrm{N}$. In the summer hemisphere equatorward of about $10^{\circ} \mathrm{S}$ in JFM and about $15^{\circ} \mathrm{N}$ in JAS, the annual mean change is larger than the seasonal change; however, the converse is true in the summer subtropics. The total PI changes in the seasons of greatest TC activity (e.g., as shown by Vecchi and Soden 2007; Xie et al. 2010) are thus significantly influenced by the seasonal responses.

The top panels in Figs. 7 and 8 show that the changes in PI are relatively small percentage wise, but the total seasonal CAPE changes reach as much as $20 \%-25 \%$ of the twentieth-century climatological values. These are quite substantial changes. Climatological CAPE need not necessarily be closely or simply related to the climatological

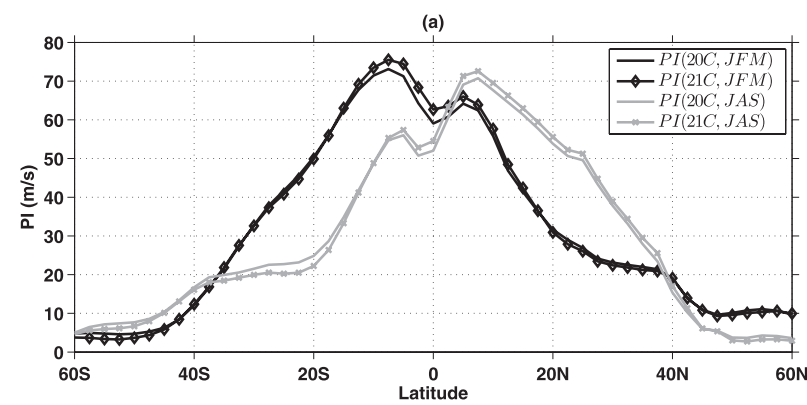

(b)

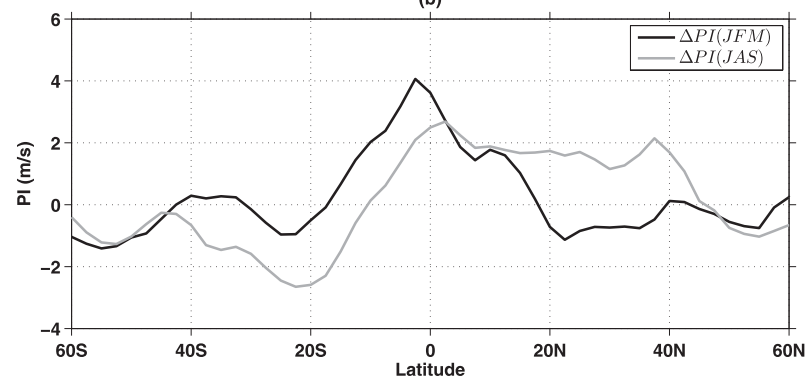

(c)

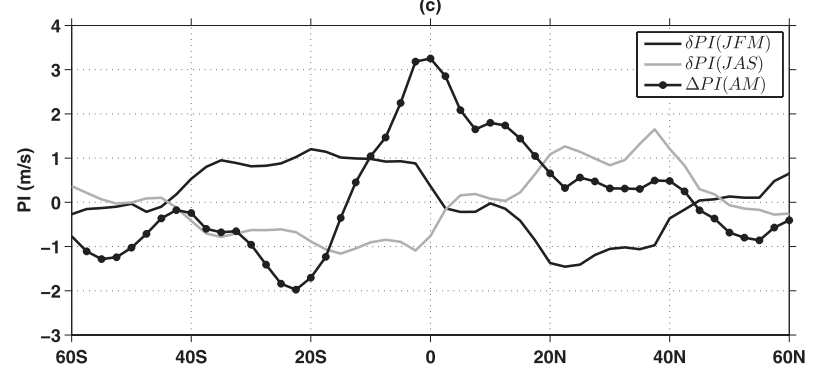

FIG. 8. (a) Zonal mean PI 20C and 21C for JFM and JAS. (b) Zonal mean PI difference 21C and 20C ( $\Delta$ PI) for JFM and JAS. (c) Zonal mean annual mean PI changes $[\Delta \mathrm{PI}(\mathrm{AM})]$ and seasonal PI changes $(\delta \mathrm{PI})$ for JFM and JAS.

mean precipitation, but we show below that the seasonal changes in these two variables have very similar structure; this is perhaps unsurprising, as they are correlated in observations on a monthly time scale (Bhat et al. 1996). Further, as CAPE places an upper bound on the kinetic energy of convective updrafts, changes in CAPE may be relevant to precipitation extremes.

Changes in tropical precipitation extremes have been found to be highly model dependent (O'Gorman and Schneider 2009; Sugiyama et al. 2009) and to vary differently with temperature than observations (Allan and Soden 2007, 2008), and thus to be uncertain in the CMIP3 ensemble. Discussion of the dynamics of these changes has tended to focus on the roles of environmental humidity and on the vertical profiles of large-scale vertical motion. The magnitude and robustness of the CAPE change suggests that this factor may be worth considering as well. Observational studies looking for CAPE trends in the twentieth century have been inconclusive because of 
(a)

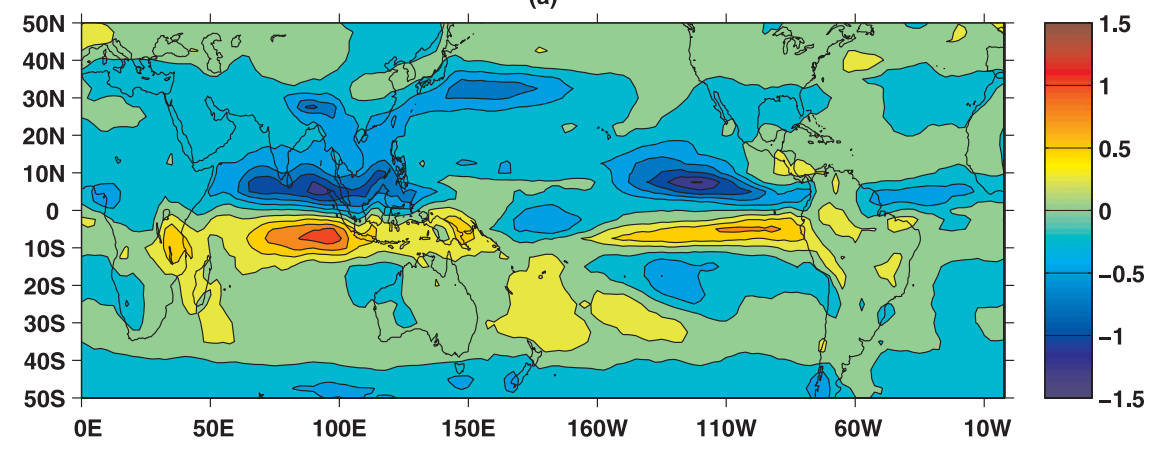

(b)

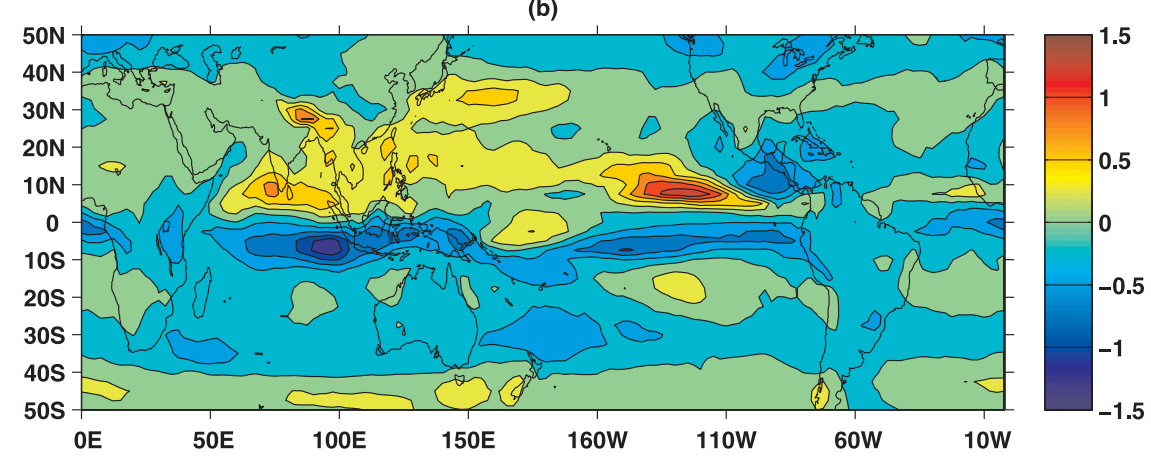

FIG. 9. Precipitation seasonal changes in (a) JFM $[\delta \operatorname{Prec}(\mathrm{JFM})]$ and (b) JAS $[\delta \operatorname{Prec}(\mathrm{JAS})]$ $\left(\right.$ contour interval $\left.=0.25 \mathrm{~mm} \mathrm{day}^{-1}\right)$.

data limitations (Gettelman et al. 2002; DeMott and Randall 2004).

\section{4) Precipitation}

Figure 9 shows the seasonal changes in the precipitation. The antisymmetry in these maps is striking and very similar to that in the SST maps (Figs. 1c and 1d). The precipitation increases in the summer hemisphere, and decreases in the winter hemisphere, as noted previously by Chou et al. (2007). As the summer hemisphere is the rainier one in the present climatology, the seasonal increases can be described as increases in regions of high precipitation and decreases in regions of low precipitation, as expected more generally (e.g., Neelin et al. 2003; Held and Soden 2006). In this case the precipitation changes are shown to be associated with SST changes with a specific dynamical cause, namely, the changes in surface wind speed.

The zonal mean precipitation changes are also shown in Fig. 10. On top of the annual mean changes, whose maximum values are around $0.5 \mathrm{~mm} \mathrm{day}{ }^{-1}$, the seasonal changes also increase the precipitation, at the location in the summer hemisphere where it peaks climatologically, by $0.4 \mathrm{~mm} \mathrm{day}^{-1}$, and decrease it by about the same amount in the winter hemisphere. As the peak climatological rainfall in the summer hemisphere is around $8 \mathrm{~mm}_{\text {day }}{ }^{-1}$, the total seasonal changes are on the order of $10 \%$. The total seasonal changes in precipitation, however, maximize slightly equatorward of the climatological seasonal precipitation maxima, as can be seen by close comparison of the top two panels of Fig. 5. Smaller (around $0.2 \mathrm{~mm} \mathrm{day}^{-1}$ ) antisymmetric changes also occur in the subtropics and midlatitudes. These precipitation changes are similar to those in CAPE discussed above, except that the maximum total seasonal changes are more nearly coincident in latitude with the climatological maxima in the case of CAPE than in the case of precipitation.

\section{Discussion}

The nature of the seasonal changes in the tropical SST and wind fields gives some clear indications about the dynamics of those changes.

Ocean dynamics seem unlikely to play a major part in the seasonal changes. Clement (2006) argues that while ocean heat transport plays an important role in the seasonal Hadley circulation of the current climate, that role can be understood well in terms of the annual mean alone; there do not appear to be large seasonal components 


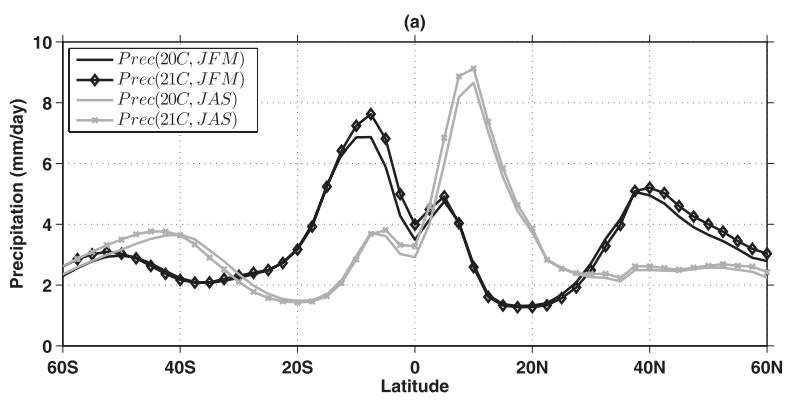

(b)

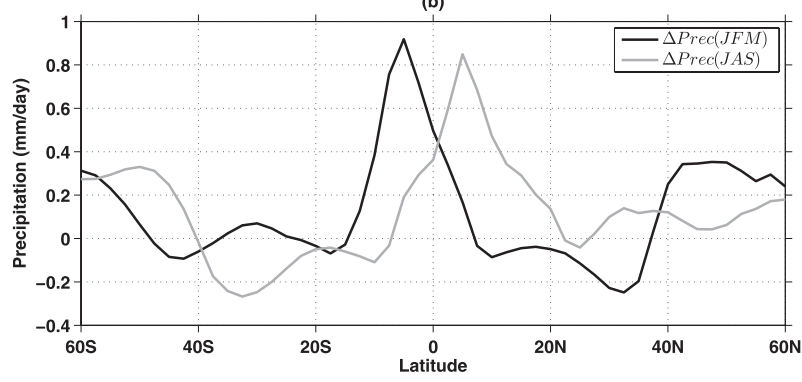

(c)

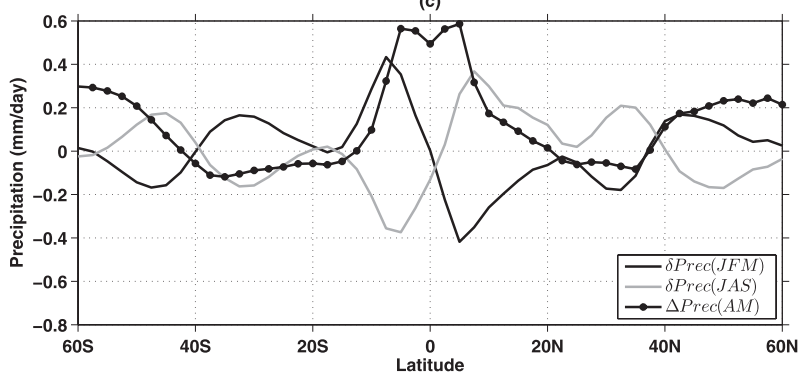

FIG. 10. (a) Zonal mean precipitation 20C and 21C for JFM and JAS. (b) Zonal mean precipitation difference $21 \mathrm{C}$ and $20 \mathrm{C}(\Delta$ Prec) for JFM and JAS. (c) Zonal mean annual mean precipitation changes $[\Delta \operatorname{Prec}(\mathrm{AM})]$ and seasonal precipitation changes $(\delta \operatorname{Prec})$ for JFM and JAS.

driven by ocean heat transport. Xie et al. (2010) show that ocean heat transport may be important in the annual mean changes (twenty-first century minus the twentieth century) in the CMIP3 ensemble, but they do not specifically address the seasonal changes in detail. The fact that the seasonal wind speed changes and SST changes appear so closely related, as shown above, suggests that the SST changes can be understood in terms of a passive ocean mixed layer forced by the atmosphere.

The view that the atmosphere is driving the seasonal changes is further supported by the fact that the interhemispheric winter Hadley circulations weaken at the same time that the SST contrasts increase, at least on the broadest scale (i.e., apart from some regions of the nearequatorial oscillations with latitude seen in Fig. 4): the seasonal SST changes are a warming of the summer hemisphere and cooling of the winter hemisphere. This would be incompatible with a view in which the Hadley circulation is driven by the SST contrast, since in that case one would expect a stronger SST contrast to be associated with a stronger Hadley circulation.

The weakening of the Hadley circulation is not inconsistent, on the other hand, with a view of the Hadley cell as being driven by changes in the surface energy budget, to the extent that those are not "compensated" by changes in radiative energy flux at the top of the atmosphere (Kang et al. 2008, 2009). The reduction in latent heat flux in the summer hemisphere and addition in the winter hemisphere reduce the energy transport the Hadley circulation needs to accomplish and thus are qualitatively consistent, all else equal, with a weakening of the circulation. Despite its internal consistency, however, this energetic view is still unsatisfying, because the changes in latent heat flux appear to be driven by surface wind speed changes, which are themselves consequences of the changes in the circulation. Further, while a reduction of energy transport in the Hadley circulation is consistent with an equatorward shift of the ITCZ (e.g., Kang et al. 2008,2009 ), as is found here, it is far from obvious that such a weakening should be accompanied by an increase in precipitation in the summer hemisphere tropics (where it is already maximum) and a decrease in the winter hemisphere tropics, leading to an overall increase in the cross-equatorial contrast in precipitation.

Rather, it appears more likely that the changes in the Hadley circulation will be best explained, one way or another, by changes in the behavior of extratropical baroclinic eddies, with momentum transports by the eddies playing a significant role. Eddy momentum transports have been found to be essential to the observed interannual variability of the Hadley circulation (Seager et al. 2003; Caballero 2007), and to the behavior of the Hadley circulation in idealized simulations of various sorts (e.g., Becker et al. (1997); Kim and Lee 2001; Walker and Schneider 2006; Schneider and Bordoni 2008; Sobel and Schneider 2009). The causes for the robust projected changes in the Hadley circulation are still debated, involving (for example) changes in the static stability of the subtropical troposphere ( $\mathrm{Lu}$ et al. 2007), tropical tropopause height (Lorenz and DeWeaver 2007; Frierson et al. 2007), and the phase speeds of eddies (Frierson et al. 2007; Chen and Held 2007; Chen et al. 2008) or stratospheric ozone (Son et al. 2008); however, all of these explanations appeal inherently to eddy dynamics and involve momentum considerations in a central way.

This evidence all suggests the following view of the chain of cause and effect, of which the tropical changes described above form several links but not the initiating ones. In a warming climate, during the near-solsticial seasons when the Hadley cells are strongest and the intertropical convergence zones are farthest from the 
equator, the winter Hadley cell expands, while both the winter and summer cells weaken. The explanation for these changes is almost certain to involve extratropical eddies in a central way, and to require consideration of momentum as well as energy. These changes in the Hadley circulation lead to changes in the surface wind speed, such that it increases in the winter subtropics and decreases in the summer subtropics. As would be expected if the ocean were to respond passively as a slab mixed layer, the summer hemisphere SST increases whereas the winter hemisphere decreases. As this increases the normal seasonal SST contrasts, CAPE, precipitation, and PI increase in the summer hemisphere.

\section{Conclusions}

We have analyzed changes in the tropical SST, surface wind, precipitation, and related fields from the twentieth to the twenty-first century in climate projections using the CMIP3 multimodel ensemble. We have focused on nearsolsticial seasons, JFM and JAS, when the Hadley cells are strongest, the intertropical convergence zones are farthest from the equator, and tropical cyclone activity is greatest. We have shown that when the annual mean changes are subtracted from the changes in these seasons, the remaining seasonal changes have a large degree of antisymmetry: the JFM changes look much like the JAS changes if either of the signs is reversed, or the fields are reflected about the equator.

The seasonal changes in SST are, broadly, an increase in the summer hemisphere and a decrease in the winter hemisphere. The resulting anomalous SST contrast is of the opposite sign to what would be expected if the SST changes were driving the Hadley circulation changes. Rather, the SST changes appear to be caused by wind speed changes-increasing wind speed in the winter hemisphere and decreasing in the summer hemisphere-which themselves are associated with previously documented changes in the Hadley circulation, namely, an expansion of the winter Hadley cell and a weakening of the summer Hadley cell. As all the mechanisms that have been proposed to explain these Hadley circulation changes involve extratropical eddies, it seems reasonable to view the tropical changes described here as induced, or at least mediated, by midlatitude dynamics.

While they do not cause the circulation changes, the seasonal SST changes do influence the atmosphere; they are associated with significant changes in precipitation, whose peak values increase in total by around $10 \%$ and shift equatorward, and even more in convective available potential energy (CAPE), which changes by as much as $25 \%$; in both cases comparable fractions of the changes are attributable to the annual mean change and the seasonal changes. Tropical cyclone potential intensity (PI) has changes that are broadly similar in structure to those in CAPE, but smaller in magnitude. The changes in SST, CAPE, precipitation, and PI oppose the annual mean changes in JFM and enhance them in JAS, so that the net changes from the twentieth to the twenty-first century are greater in JAS and smaller in JFM.

Acknowledgments. We thank Michela Biasutti and Hamish Ramsay for discussions and Naomi Naik for her help with the CMIP3 dataset. We thank the reviewers for their comments on an earlier version of this paper. We acknowledge the modeling groups, the Program for Climate Model Diagnosis and Intercomparison (PCMDI) and the WCRP's Working Group on Coupled Modelling (WGCM), for their roles in making available the WCRP CMIP3 multimodel dataset. Support of this dataset is provided by the Office of Science, U.S. Department of Energy. SJC and AHS acknowledge support from NOAA Grant NA08OAR4320912, and AHS acknowledges additional support from NSF Grant AGS-0946849.

\section{REFERENCES}

Allan, R. P., and B. J. Soden, 2007: Large discrepancy between observed and simulated precipitation trends in the ascending and the descending branches of the tropical circulation. Geophys. Res. Lett., 34, L18705, doi:10.1029/2007GL031460.

- and - 2008: Atmospheric warming and the amplification of precipitation extremes. Science, 321, 1481-1484.

Becker, E., G. Schmitz, and R. Geprags, 1997: The feedback of midlatitude waves onto the Hadley cell in a simple general circulation model. Tellus, 49A, 182-199.

Bhat, G. S., J. Srinivasan, and S. Gadgil, 1996: Tropical deep convection, convective available potential energy and sea surface temperature. J. Meteor. Soc. Japan, 74, 155-166.

Biasutti, M., and A. H. Sobel, 2009: Delayed Sahel rainfall and global seasonal cycle in a warmer climate. Geophys. Res. Lett., 36, L23707, doi:10.1029/2009GL041303.

, - - and S. J. Camargo, 2009: The role of the Sahara low in summertime Sahel rainfall variability and change in the CMIP3 models. J. Climate, 22, 5755-5771.

Bister, M., and K. A. Emanuel, 1998: Dissipative heating and hurricane intensity. Meteor. Atmos. Phys., 52, 233-240.

_ and _ 2002a: Low frequency variability of tropical cyclone potential intensity. 1. Interannual to interdecadal variability. J. Geophys. Res., 107, 4801, doi:10.1029/2001JD000776.

$\longrightarrow$, and $-2002 \mathrm{~b}$ : Low frequency variability of tropical cyclone potential intensity. 2. Climatology for 1982-1995. J. Geophys. Res., 107, 4621, doi:10.1029/2001JD000780.

Caballero, R., 2007: Role of eddies in the interannual variability of Hadley cell strength. Geophys. Res. Lett., 34, L22705, doi:10.1029/2007GL030971.

Chen, G., and I. M. Held, 2007: Phase speed spectra and the recent poleward shift of Southern Hemisphere surface westerlies. Geophys. Res. Lett., 34, L21805, doi:10.1029/2007GL031200.

, J. Lu, and D. M. W. Frierson, 2008: Phase speed spectra and the latitude of surface westerlies: Interannual variability and global warming trend. J. Climate, 21, 5942-5959. 
Chou, C., J. D. Neelin, J.-Y. Tu, and C.-T. Chen, 2006: Regional tropical precipitation change mechanisms in ECHAM4/ OPYC3 under global warming. J. Climate, 19, 4207-4223.

- J.-Y. Tu, and P.-H. Tan, 2007: Asymmetry of tropical precipitation change under global warming. Geophys. Res. Lett., 34, L17708, doi:10.1029/2007GL030327.

Clement, A. C., 2006: The role of the ocean in the seasonal cycle of the Hadley circulation. J. Atmos. Sci., 63, 3351-3365.

— A. A. Baker, and J. Leloup, 2010: Climate change: Patterns of tropical warming. Nat. Geosci., 3, 8-9.

DeMott, C. A., and D. A. Randall, 2004: Observed variations of tropical convective available potential energy. J. Geophys. Res., 109, D02102, doi:10.1029/2003JD003784.

Dima, I., and J. M. Wallace, 2003: On the seasonality of the Hadley cell. J. Atmos. Sci., 60, 1522-1527.

DiNezio, P. N., A. C. Clement, G. A. Vecchi, and B. J. Soden, 2009: Climate response of the equatorial Pacific to global warming. J. Climate, 22, 4873-4892.

Emanuel, K. A., 1995: Sensitivity of tropical cyclones to surface exchange coefficients and a revised steady-state model incorporating eye dynamics. J. Atmos. Sci., 52, 3969-3976.

Frierson, D. M. W., J. Lu, and G. Chen, 2007: Width of the Hadley cell in simple and comprehensive general circulation models. Geophys. Res. Lett., 34, L18804, doi:10.1029/2007GL031115.

Gettelman, A., D. J. Seidel, M. C. Wheeler, and R. J. Ross, 2002: Multidecadal trends in tropical convective available potential energy. J. Geophys. Res., 107, 4606, doi:10.1029/2001JD001082.

Held, I. M., and B. J. Soden, 2000: Water vapor feedback and global warming. Annu. Rev. Energy Environ., 25, 441-475.

— and - 2006: Robust responses of the hydrological cycle to global warming. J. Climate, 19, 5686-5699.

$\mathrm{Hu}$, Y., and Q. Fu, 2007: Observed poleward expansion of the Hadley circulation since 1979. Atmos. Chem. Phys., 7, 5229-5236.

Hurley, J. V., and J. Galewsky, 2010: A last-saturation diagnosis of subtropical water vapor response to global warming. Geophys. Res. Lett., 37, L06702, doi:10.1029/2009GL042316.

Ihara, C., and Y. Kushnir, 2009: Change of mean midlatitude westerlies in 21st century climate simulations. Geophys. Res. Lett., 36, L13701, doi:10.1029/2009GL037674.

Johanson, C. M., and Q. Fu, 2009: Hadley cell widening: Model simulations versus observations. J. Climate, 22, 2713-2725.

Kang, S. M., I. M. Held, and D. M. W. Frierson, 2008: The response of the ITCZ to extratropical thermal forcing: Idealized slabocean experiments with a GCM. J. Climate, 21, 3521-3532.

, D. M. W. Frierson, and I. M. Held, 2009: The response of the ITCZ to extratropical thermal forcing in an idealized GCM: The importance of radiative feedbacks and convective parameterization. J. Atmos. Sci., 66, 2812-2827.

Kim, H., and S. Lee, 2001: Hadley cell dynamics in a primitive equation model. Part II: Nonaxisymmetric flow. J. Atmos. Sci., 58, 2859-2871.

Kushner, P. J., I. M. Held, and T. L. Delworth, 2001: Southern Hemisphere atmospheric circulation response to global warming. J. Climate, 14, 2238-2249.

Leloup, J., and A. Clement, 2009: Why is there a minimum in projected warming in the tropical North Atlantic Ocean? Geophys. Res. Lett., 36, L14802, doi:10.1029/2009GL038609.

Lindzen, R. S., and S. Nigam, 1987: On the role of sea surface temperature gradients in forcing low-level winds and convergence in the tropics. J. Atmos. Sci., 44, 2418-2436.

Liu, Z., S. Vavrus, F. He, N. Wen, and Y. Zhong, 2005: Rethinking tropical ocean response to global warming: The enhanced equatorial warming. J. Climate, 18, 4684-4700.
Lorenz, D. J., and E. T. DeWeaver, 2007: Tropopause height and zonal wind response to global warming in the IPCC scenario integrations. J. Geophys. Res., 112, D10119, doi:10.1029/ 2006JD008087.

Lu, J., G. A. Vecchi, and T. Reichler, 2007: Expansion of the Hadley cell under global warming. Geophys. Res. Lett., 34, L06805, doi:10.1029/2006GL028443.

Meehl, G. A., C. Covey, T. Delworth, M. Latif, B. McAvaney, J. F. B. Mitchell, R. J. Stouffer, and K. E. Taylor, 2007: The WCRP CMIP3 multimodel dataset: A new era in climate change research. Bull. Amer. Meteor. Soc., 88, 1383-1394.

Mitas, C. M., and A. Clement, 2005: Has the Hadley cell been strengthening in recent decades? Geophys. Res. Lett., 32, L03809, doi:10.1029/2004GL021765.

_ - and —, 2006: Recent behavior of the Hadley cell and tropical thermodynamics in climate models and reanalyses. Geophys. Res. Lett., 33, L01810, doi:10.1029/2005GL024406.

Neelin, J. D., C. Chou, and H. Su, 2003: Tropical drought regions in global warming and El Niño teleconnections. Geophys. Res. Lett., 30, 2275, doi:10.1029/2003GL018625.

O'Gorman, P. A., and T. Schneider, 2009: The physical basis for increases in precipitation extremes in simulations of 21stcentury climate change. Proc. Natl. Acad. Sci. USA, 106, 14 773-14 777

Richter, I., and S.-P. Xie, 2008: Muted precipitation increase in global warming simulations: A surface evaporation perspective. J. Geophys. Res., 113, D24118, doi:10.1029/2008JD010561.

Schneider, T., and S. Bordoni, 2008: Eddy-mediated regime transitions in the seasonal cycle of a Hadley circulation and implications for monsoon dynamics. J. Atmos. Sci., 65, 915-934.

Seager, R., N. Harnik, Y. Kushnir, W. Robinson, and J. Miller, 2003: Mechanisms of hemispherically symmetric climate variability. J. Climate, 16, 2960-2978.

Seth, A., M. Rojas, and S. A. Rauscher, 2010: CMIP3 projected changes in the annual cycle of the South American monsoon. Climatic Change, 98, 331-357.

— S. A. Rauscher, M. Rojas, A. Giannini, and S. J. Camargo, 2011: Enhanced spring convective barrier for monsoons in a warmer world? Climatic Change, in press, doi:10.1007/ s10584-010-9973-8.

Sherwood, S. C., W. Ingram, Y. Tsushima, M. Satoh, M. Roberts, P. L. Vidale, and P. A. O'Gorman, 2010a: Relative humidity changes in a warmer climate. J. Geophys. Res., 115, D09104, doi:10.1029/2009JD012585.

, R. Roca, T. M. Weckwerth, and N. G. Andronova, 2010b: Tropospheric water vapor, convection, and climate. Rev. Geophys., 48, RG2001, doi:10.1029/2009RG000301.

Sobel, A., 2007: Simple models of ensemble-averaged tropical precipitation and surface wind. The Global Circulation of the Atmosphere, T. Schneider and A. H. Sobel, Eds., Princeton University Press, 219-251.

__ , and T. Schneider, 2009: Single-layer axisymmetric model for a Hadley circulation with parameterized eddy momentum fluxes. J. Adv. Model. Earth Syst., 1, doi:10.3894/ JAMES.2009.1.10.

Soden, B. J., D. L. Jackson, V. Ramaswamy, M. D. Schwarzkopf, and X. Huang, 2005: The radiative signature of upper tropospheric moistening. Science, 310, 841-844.

Son, S.-W., and Coauthors, 2008: The impact of stratospheric ozone recovery on the Southern Hemisphere westerly jet. Science, 320, $1486-1489$.

Sugiyama, M., H. Shiogama, and S. Emori, 2009: Precipitation extreme changes exceeding moisture content increases in 
MIROC and IPCC climate models. Proc. Natl. Acad. Sci. USA, 107, 571-575.

Vecchi, G. A., and B. J. Soden, 2007: Effect of remote sea surface temperature change on tropical cyclone potential intensity. Nature, 450, 1066-1070.

A. T. Wittenberg, I. M. Held, A. Leetmaa, and M. J. Harrison, 2006: Weakening of tropical Pacific atmospheric circulation due to anthropogenic forcing. Nature, 441, 73-76, doi:10.1038/nature04744.

Walker, C. C., and T. Schneider, 2006: Eddy influences on Hadley circulations: Simulations with an idealized GCM. J. Atmos. Sci., 63, 3333-3350.
Wright, J., A. H. Sobel, and J. Galewsky, 2010: Diagnosis of zonal mean relative humidity changes in a warmer climate. J. Climate, 23, 4556-4570.

Xie, S.-P., and G. H. Philander, 1994: A coupled ocean-atmosphere model of relevance to the ITCZ in the eastern Pacific. Tellus, 46A, 340-350.

, C. Deser, G. A. Vecchi, J. Ma, H. Teng, and A. T. Wittenberg, 2010: Global warming pattern formation: Sea surface temperature and rainfall. J. Climate, 23, 966-986.

Yin, J. H., 2005: A consistent poleward shift of the storm tracks in simulations of 21st century climate. Geophys. Res. Lett., 32, L18701, doi:10.1029/2005GL023684. 